\title{
EL TURISMO COMUNITARIO EN EL NORDESTE BRASILEÑO
}

\author{
Luzia Neide Coriolano \\ Dra em Geografia, Coordenadora do Mestrado \\ em Turismo da UECE, Pesquisadora do CNPq.
}

\section{Resumen}

El siguiente artículo tiene por objetivo caracterizar los procesos de desarrollo del turismo comunitario en el nordeste Brasileño, tomando como referencias experiencias en Brasil y fuentes secundarias que complementan los ánalisis sobre los beneficios del turismo para las comunidades locales, como también las comprensiones sobre el turismo comunitario. Se concluye que el turismo no es una causa de desarrollo, sino un factor complementario y dependiente del desarrollo en general de un país. Así también, el turismo como actividad conlleva a que distintos sujetos ejerzan situaciones de conflicto por el dominio de espacios, como por ejemplo, sucede con áreas protegidas, que son reconocidas como terrenos baldíos, habitados por nadie según el Estado, y que no reconocen su uso ni habitabilidad previa por parte de comunidades tradicionales. Así también, sucede cuando la especulación inmobiliaria se apodera capitalistamente del turismo, usando a las comunidades locales como mano de obra barata, en este caso el turismo comunitario puede ser una alternativa, dado que se basa de la realidad de un territorio y no solo de la abstracción teórica sobre los beneficios del turismo. Finalmente, se sistematizan los principios en los que se basa el turismo comunitario.

Palabras clave: Turismo Comunitario, nordeste Brasileño, Principios.. 


\title{
COMMUNITY BASED TOURISM IN THE BRAZILIAN NORTHEAST
}

\author{
Luzia Neide Coriolano \\ Dra em Geografia, Coordenadora do Mestrado \\ em Turismo da UECE, Pesquisadora do CNPq.
}

\section{Resumen}

This research aims characterize procesess of development of community based tourism in the Brazilian Northeast, taking as reference experiences in Brazil and secondary sources that complement the analysis about benefits of tourism for local communities, as well as the understandings about community based tourism. It is concluded that tourism is not a cause of development, but a complementary factor and dependent of the overall development of a country. Tourism as an activity means that different subjects exercise situations of conflict due to the domination of spaces, such as protected areas, which are recognized as vacant lands, inhabited by no one according to the State, and that do not recognize their use or previous habitability by traditional communities. This happens too when tourism is used in a capitalist way trough real state especulation, using local communities as cheap labor, in this case community based tourism can be an alternative, based on reality of a territory and not just based of theoretical abstraction about benefits of tourism. Finally, the principles of community based tourism were systematized.

Keywords: Community Based Tourism, Brazilian Northeast, Principles. 


\section{Introducción}

La re valorización de la costa en el Noreste de Brasil para el ocio y el turismo, por la reestructuración capitalista amplió la disputa de este espacio para nuevos usos, y hizo de él el principal producto inmobiliario. Se produjo una transformación de la costa del Noreste, segregando y expropiando poblaciones nativas o tradicionales de cara al reacomodo necesario para la ocupación turística que se apropia de los mejores lugares, los considerados más bellos y atractivos. El turismo fue instalado en estos lugares, formando centros receptivos de turismo para donde siguen flujos turísticos de las agencias de viajes, dirigidos por guías turísticos.

En el Noreste, especialmente en Ceará, este hecho ocurrió de forma arbitraria y centralizada bajo el mando de intereses extranjeros. Por ejemplo, en Jericoacoara y en Canoa Quebrada, Ceará, las zonas turísticas de mayor expresión, dirigidas a las demandas internacionales fueron el blanco de la masiva presencia de empresarios extranjeros, tanto turistas como empresarios vendedores de servicios dominando o sumergiendo el mercado turístico local. Las dos comunidades de pescadores, además de ser desposeídos de sus tierras, sus espacios fueron descaracterizados por la construcción de nuevos emprendimientos, de grandes proyectos turísticos. Estos mega proyectos dirigen la actual estructura territorial que ocupan gran parte de la tierra de estos pueblos. Instrumentos jurídicos están en manos de propietarios extranjeros, teniendo éstos, gran facilidad jurídica para adquirir propiedades que están destinados para la construcción de hoteles, condominios privados, restaurantes, discotecas, bares, centros comerciales, centros de convenciones, edificios siendo que muchos de ellos se encuentran en zonas de construcciones prohibidas en la costa. Brasil se está consolidando como un nuevo mercado para el turismo llamado residencial o inmobiliario, que tienen los ingleses como principales compradores mundiales, propietarios de inmuebles fuera de Inglaterra. Las adquisiciones de los europeos de propiedades para segundas residencias en el extranjero crecen cada año, lo que significa nuevos inmuebles y ventas del mercado inmobiliario internacional y requiere, por lo tanto, estudios e investigaciones, pues expropia a los brasileños, pareciendo para muchos otra forma de colonizar.

Los gobiernos, generalmente, se posicionan a favor de estos emprendimientos hoteleros transnacionales y facilitan lo que sea necesario para garantizar la atracción del capital extranjero, asegurando la infraestructura básica de servicios urbanos relacionado con el transporte urbano, comunicaciones, abastecimiento de agua potable, pavimentación, alcantarillado, etc . Parten de la premisa de que estos emprendimientos son los motores del desarrollo. Contradictoriamente se da un proceso de descaracterización de las comunidades pesqueras para la implantación de infraestructura para el turismo, como ha ocurrido en el otros centros en el Noreste orientados al turismo internacional, como 
la playa de Porto de Galinhas, en Pernambuco; playa de Pipa, en Rio Grande do Norte; Troncoso, Arraial D'Juda, Grarajuba, Itacaré, Porto Seguro, Praia do Forte, en Bahía; y Maragogi en Alagoas.

\section{EI hospedaje y la apropiación de espacios}

De todas las actividades del turismo el hospedaje es el más llamativo por exigir la apropiación de espacios, es decir, producir territorios, y por ser en torno de ella que gravitan los otros servicios. La oferta de hospedaje no significa apenas tener el espacio para dormir, sino para jugar y consumir una gran cantidad de bienes y servicios que el turista necesita para salir de casa, pero sobre todo objetos inducidos por el mercado, transformando así los hoteles en mini-centros comerciales. El poder simbólico del turismo de acuerdo con Bourdier (2000) ayuda a construir los sueños de los turistas, pues funciona astutamente convertido en cómplices aquellos que a él se someten.

Los resorts son grandes complejos hoteleros, verdaderas obras arquitectónicas que utilizan muchos espacios, porque entienden el hospedaje en el sentido pleno, maneras de dar placer a los huéspedes. Se multiplicaron los espacios especializados para las más diversas situaciones, surgiendo los campos de golf, salones de belleza, spas, salones de tenis, juegos, discotecas, gimnasios, centros de convenciones, cines, tiendas, o sea, una variedad de ambientes de bienes y servicios. Encabezando sofisticadas formas de hospedajes, tales como condo-hoteles que ofrecen condominios en tiempo compartido, flats, administrados por las propias cadenas hoteleras, condominios privados y casas privadas de turistas. Estas organizaciones tienen dificultades en la forma de computar datos estadísticos del sector, ya que no entran en la categoría de hospedaje, ya que los propietarios tienen derecho al libre uso de la propiedad por algunos años, y por lo tanto adquieren en apariencia una categoría diferente de turismo. Y así hay inmigrantes que se hacen pasar por turistas, y viceversa, por lo que es difícil saber lo que son y lo que hacen en el país. Estos espacios están dirigidos al turista convencional, que es capaz de consumir ocio y le gusta el distanciamiento de la población residente.

En Brasil, el turismo crece y se fortalece como actividad generadora de riqueza, convirtiéndose en un importante producto de exportación. En el nordeste de Brasil, especialmente en Ceará (estado emergente para el turismo interno), el turismo ocupa el cuarto lugar entre los productos de exportación ${ }^{1}$. Sin embargo, cuanto más se torna una estrategia de desarrollo económico, más se reduce su imagen al tamaño de mercadotecnia. El empobrecimiento de significados para el sector se puede ver en los programas de gobierno, en las prácticas del llamado trade turístico, en los comportamientos de los

1 El primer ítem de exportación es el calzado, el segundo los productos textiles y el tercero la castaña de caju. Después del turismo son productos de exportación: cuero y pieles, camarón, langostas, frutas tropicales, confecciones, ceras vegetales y hierro. 
empresarios de la cadena de producción. Las consecuencias de este reduccionismo son desastrosas para la actividad del turismo, que en la esfera pública, se considera un gran "negocio" reduciendo políticas públicas en mera acción de marketing, para la venta del destino turístico. En el espacio privado, la cadena productiva del turismo está estructurada sobre las mismas bases de las economías de los sectores primario y secundario. Así, los proyectos públicos y privados para el sector turístico se construyen por los modelos mentales y bases semánticas de la economicidad que transforma la tierra, lugares, viajes, sueños, imágenes en mercancías. Los discursos políticos, jurídicos y económicos se justifican por esta misma forma de pensar con respecto a las cuestiones de sostenibilidad ambiental, marcados por la vaguedad, la ambigüedad, omisión. Muestran así, la incapacidad para resolver los problemas socio-ambientales y cuanto al establecimiento de normas e institucionalización efectiva de los servicios turísticos.

Los países pobres son llevados a creer en el turismo como una actividad que induce el desarrollo, lo que no ocurre, pues sabemos que el desarrollo económico tiene base en las actividades productivas sólidas, con un gran apoyo en la industrialización. Y que primero el lugar necesita crecer y desarrollarse para poder el turismo establecerse con éxito. Incluso más que la historia del turismo en las comunidades costeras ha revelado el abuso del poder económico en el proceso de especulación de la tierra para el ocio, teniendo la problemática de la expropiación de tierras uno de los factores de explotación económica de renta de la tierra y de la mano de obra, habiendo desencadenado el proceso de organización del turismo comunitaria como una actividad de defensa y de reacción al turismo invasor de comunidades. El turismo comunitario surge como contraposición al llamado turismo de los resorts y de los megaempreendimentos y como medio de evitar que emprendedores externos dominen las comunidades. Algunas comunidades costeras maltratadas por el proceso de especulación inmobiliaria, en nombre del turismo, crean un nuevo eje de turismo - el turismo alternativo o comunitario, por lo que, asociado a la lucha por la propiedad de las tierras costeras, y gestados por las comunidades.

\section{El turismo comunitario: un nuevo eje}

En Brasil, muchas comunidades son parte de esta Red de Turismo Comunitario destacándose entre estos sujetos sociales algunos movimientos sociales, comunidades, operadores de viajes, operadores del comercio justo, de economías solidarias, organizaciones ambientalistas y organizaciones no gubernamentales, todos ellos comprometidos con esta tarea de encontrar otros caminos para el desarrollo. Como por ejemplo: Pedras Negras en el Vale do Guaporé (Rondônia), Mamirauá y Silves en Amazonas, Ilha de Cotijuba en Belém, Diogo Lopes en Rio Grande do Norte, y las comunidades de Ponta Grossa, Tremembé, Tatajuba, Balbino, Batoque, Coqueirinho, 
Conjunto Palmeiras, Nova Olinda, Barra das Moitas, Caetanos de Cima, Curral Velho, Praínha do Canto Verde, en Ceará. Sampaio (2005) destaca el Proyecto de Turismo Acolhida en Colônia con sede en Santa Rosa de Lima (SC), el Proyecto de Turismo Comunitario (en el ambito de la Agenda 21) de la Comunidad Lagoa de Ibiraquera en los municipios de Imbituba y Garopaba en Santa Catarina - el Proyecto Zona do Laboratorio de Educação para o Ecodesenvolviemiento en la Micro-cuenca del Río Sagrado, Morretes, Paraná.

Si los grandes hoteles y resorts simbolizan la acumulación y concentración del capital en el sector turístico, las posadas o pequeños hoteles pueden simbolizar las nuevas imágenes de un turismo menos concentrado y más solidario, menos pasteurizado y más conscientes de la diversidad cultural. El turismo no sólo mapea territorios, sino que crea la territorialidad, como define destinos, ofrece excursiones, dando visibilidad al espacio que antes era "invisible". Además de la construcción de espacios simbólicos, la actividad turística teje la extensa red de pequeñas empresas que, a su vez, crea sociabilidad a las más diversas. Así, siguen los dos ejes del turismo: el globalizado y de base comunitaria, que en efervescencia se contraponen y se complementan, lo que muchos gobiernos no consiguen aprender.

Muchos creen que la actividad se introdujo en las comunidades como una alternativa para la generación de empleo e ingresos para los residentes, pues fue tornada como verdadera la idea de que el turismo se configura como una gran oportunidad de empleos para la población local. Ocurre en los países periféricos, intensa competencia entre regiones y lugares para ser receptores de los grandes proyectos y desarrollos turísticos. Es por ello que las comunidades que no están incluidas en los itinerarios de turismo convencional luchan para incluirse y atraer visitantes a comprar sus productos, que prueben la comida típica de la zona, adquieran artesanías, usen el hospedaje y disfruten de la naturaleza o el paisaje con senderos para paseos. Surgieron así los arreglos productivos de base comunitaria, que están más allá del modelo de arreglos productivos locales, pues son totalmente ajenos a los procedimientos y normas, y no se ajustan a los conceptos ya institucionalizados de APLs.

Los fundamentos de la ideología del turismo se dan a conocer asegurando que esta actividad económica además de generar empleo e ingresos y promover el desarrollo, es capaz de promover un desarrollo ecológicamente sostenible, porque no contaminan el medio ambiente como la actividad industrial y no degrada la naturaleza como la agricultura. Estos son argumentos fuertes que apoyan la ideología del turismo y convence a las comunidades para desarrollar actividades turísticas a menudo abandonando las anteriores, especialmente las tradicionales básicas y más sostenibles, lo que ha creado

graves problemas sociales y ambientales. En este impasse, los pescadores se transforman 
en camareros, jardineros, vigilantes; las artesanas en camareras, meseras, negando las actividades tradicionales. Así el turismo, en las comunidades ha sido una actividad difícil, a veces perturbadora de las actividades tradicionales y sus resultados no siempre son satisfactorios, lo que según CAZES $(1999$, p. 80) afirma que:

Un cálculo detallado de las cuentas externas del turismo, teniendo en cuenta el conjunto de entradas y salidas financieras generadas por la recepción del turismo internacional, lleva más a menudo a confirmar el pensamiento pesimista de François Ascher: no es el turismo que permite el desarrollo, pero es el desarrollo general de un país que hace que el turismo sea rentable.

Como el turismo globalizado es convertido para los mega emprendimientos llega a los países llamados en desarrollo sin tener en cuenta las ocupaciones anteriores, no ofrece oportunidades y beneficios para las comunidades costeras, porque no las incluye en sus proyectos, han creado en algunas de ellas, reacción negativa al turismo global, que paso a ser visto como una amenaza a su forma de vida. Así muchas comunidades, especialmente en el Noreste y el Norte de Brasil, las regiones mas injusticiadas socialmente, inventaron una forma diferente de organizar la actividad, el turismo comunitario en defensa de las poblaciones costeras y ribereñas. Programaron el turismo con base local, que se convierte para la oferta de servicios, tours, entretenimientos relacionados con los valores de los residentes, priorizando lo rústico y no el lujo. Asociado a las actividades que respetan a la sostenibilidad socio-espacial, dando prioridad a los valores culturales y descubriendo formas inteligentes de participación en la cadena de producción turística, con productos diferenciados. Y, sobre todo, con su propia visión del lugar, del ocio y turismo. Un turismo que no sólo se dirija al consumo, sino al intercambio de experiencias, fortalecimiento de los lazos de amistad y apreciación cultural.

\section{Qué es el turismo comunitario?}

Por lo tanto, el turismo comunitario es aquel en el que las comunidades de forma asociada organizan arreglos productivos locales, poseen el control efectivo de las tierras y de las actividades económicas asociadas a la explotación del turismo. En ella, el turista es llevado a interactuar con el lugar y con las familias, ya sean los pescadores, ribereños, pantaneiros (hombre de campo de la región del Pantanal en Brasil) o los indios. Una de las primeras acciones que las comunidades realizan es la elaboración de un acuerdo interno entre los propios residentes en defensa de sus propiedades 
Todos están comprometidos con la preservación de sus tierras, no deshacerse de ella, y aquellos que precisan realmente venderla someten el negocio a la evaluación de la comunidad, que examina quién es el comprador, comprueba si el comprador puede ser un asociado, y cómo puede ser hecha la asociación. Siendo este nuevo propietario médico, maestro, ingeniero o cualquier profesión, que deseen establecerse allí para el veraneo, pregunta si él se identifica con los objetivos de la comunidad, convencen al nuevo residente que sin eso no tendría sentido su presencia allí. Algunos desisten de la compra, pero los que compran están entusiasmados, se comprometen y ayudan a crecer la comunidad. Atender enfermos durante tres horas los fines de semana en una comunidad se convierte en placer. Enseñar a plantar adecuadamente, o seleccionar semillas para la plantación, participar de campañas educativas, a participar en los esfuerzos conjuntos son las formas de colaboración con la comunidad, vista como un buen pasatiempo, como gesto solidario necesario. Algunas comunidades cuentan con estas normas por escrito en los Estatutos de la Asociación de Vecinos y otras no, pues cuando las inmobiliarias llegan con escrituras del notario diciendo que ellos son dueños de la tierra, estas escrituras son falsas, lo que lleva a desacreditar la validez de los documentos que son adquiridos por métodos oscuros.

Resultado fundamental para el adelanto del turismo en la costa fue la decadencia y desaparición de muchas actividades económicas tradicionales como la pesca, los ingresos, mediante la sustitución de actividades relacionadas con hoteles, posadas, restaurantes y bares. Comunidades costeras, que siempre han vivido de la pesca, la agricultura de subsistencia, de la artesanía, terminan abandonando estos trabajos tradicionales, para la concurrencia patrocinada por la pesca industrial, y por la pérdida de las tierras con adquisición de terrenos y el desalojo de los pescadores y sus familias de la playa. Tal arbitrariedad fue llevada a cabo por la especulación inmobiliaria, vinculada al ocio y el turismo, o sea, para la implantación de los centros turísticos, resorts, parques acuáticos, restaurantes, tiendas, en otras empresas. Se ejecuta como una interrupción de las economías locales, junto con el proceso de cambio en el uso y la ocupación de la costa.

En el turismo comunitario los residentes tienen el control de la actividad productiva, desde la planificación para el desarrollo y la gestión de los arreglos de producción. Por lo tanto, pueden mejorar sus economías, las oportunidades para el lugar, y se preocupan para que todos participen, no de forma individual, de ahí, el avance para las gestiones integradas de los arreglos productivos que se convierten en comunitarios, y facilitan los enfrentamientos. Realizan proyectos que garantizan la mejora de las condiciones de vida del local, además de preparar condiciones para recibir a los visitantes y turistas de una manera más digna. A diferencia de la forma que hace casi tres décadas viene ocurriendo en el Noreste, con el crecimiento del turismo mundial, que explora la fuerza laboral de hombres y mujeres mal remunerados, y con horarios de trabajo pesado para cumplir con los turistas que juegan, caminan, comen y beben sin preocuparse por la hora, pues el 
turista viaja para jugar, y debe tener sus necesidades atendidas.

En el turismo globalizado, los residentes involucrados en la actividad no siempre mejoran sus condiciones de trabajo, siguen viviendo en áreas desestructuradas con condiciones precarias en sus propios hogares y en la comunidad. Muchos de ellos trabajan mucho, incluidos jóvenes y niños, habiendo algunos casos de explotación sexual. Así el turismo acontece en la periferia del capitalismo, con niveles crecientes de explotación humana y segregación espacial. Castells $(1999$, p. 182) muestra con relación al turismo internacional, que a menudo esa explotación llega a los propios niños, diciendo que:

La globalización de las actividades económicas ofrece oportunidad de mejora sustancial en el empleo de niños, obtenidos a partir de las diferencias entre el costo de mano de obra infantil en los países en desarrollo y el precio de los bienes y servicios cobrados en mercados más ricos. Este es claramente el caso del sector de turismo internacional. Los servicios de lujo de los cuales los turistas de un ingreso medio pueden disfrutar en muchos "paraísos tropicales" dependen, en gran medida, de la sobre explotación de la mano de obra local, incluyendo un número significativo de niños.

En muchos centros receptores de turismo convencional los niños venden recuerdos, actúan como guías, trabajan en restaurantes. Basta visitar el Pelourinho en Salvador, Olinda en Pernambuco, y las playas de Ceará para ver tal arbitrariedad. En el turismo comunitario, el interés se vuelve para el trabajo de los adultos para mejorar los ingresos de las familias, y los niños son preservados de la anticipación del trabajo. Las actividades turísticas comunitarias están relacionadas con otras actividades económicas, con iniciativas que fortalezcan la agricultura, la pesca y la artesanía, tornando estas actividades preexistentes al turismo más sostenible. Da prioridad a la creación de empleos para los residentes, los pequeños emprendimientos locales, la promoción del capital local, la garantía de la participación de todos, dando también espacio a las mujeres y los jóvenes. Asegura la participación de personas de las comunidades con la planificación descentralizado y asociativa, lucha por la regulación de la tierra costeras, muchas de marinas, por la garantía de la tenencia de la tierra de los pueblos indígenas, pesqueros, las llamadas comunidades nativas. Buscar el reglamento de áreas protegidas, así como organizar comités para cuidar de la gestión ambiental de sus espacios, con planes de manejos y de conservación compatibles con el turismo. 


\section{Las referencias de turismo comunitario}

La comunidad de Canto Verde, en Ceará, situada a $126 \mathrm{~km}$ de Fortaleza, capital del estado, una típica colonia de pescadores artesanales es una referencia al turismo comunitario, y lidera un grupo de comunidades. Allí una población de 1.100 personas que viven del mar y dependen de él. Se destaca por la pesca de langosta, aunque pesquen otras especies. Con la ayuda de la ONG - TERRAMAR - líder de la red de destinos de turismo comunitario en Ceará, en articulación con otras redes, de Latino América, africanas, europeas e integra la Red de Destinos Comunitarios en Brasil. Las comunidades experimentan, así, nuevas formas de producción de servicios turísticos, no estandarizados, con bastante creatividad, compromiso y solidaridad. El turismo comunitario es un proceso de descubrimiento, cuando la comunidad discute lo que quiere y lo que puede hacer para el desarrollo de las personas y del lugar.

Así, al lado del turismo mundial avanza a pasos largos el turismo de base comunitaria, especialmente en el Noreste y en el Norte del país, especialmente en Ceará, que tiene la especificidad de ser celebrado de forma solidaria, mostrando signos de otro turismo. Maldonado (1993, p. 34) en estudios sobre núcleos pesqueros, resalta que la noción de lugar es fundamental en el análisis de comunidades, pues revela la existencia local de los fenómenos tanto en el espacio físico como del espacio social "confiriendo esencia, significado y trascendencia, porque es localmente que nos situamos y es localmente que las cosas suceden". Se añadiría que, es localmente, que se puede ver, en lo empírico, las contradicciones del mundo, recordaba Santos (2008, p.161) diciendo "hoy, sin duda más importante de lo que la conciencia del lugar es la conciencia del mundo, obtenida a través del lugar". Las comunidades se preocupan con este debate para la comprensión y formación de esa conciencia, además de recibir un seguimiento sistemático de colaboradores vinculados a las ONGs, iglesias, universidades, para apoyo tecnológico, jurídico, teórico e ideológico.

Las contradicciones de la sociedad de consumo, sin embargo, se reproducen en las comunidades, ya que el capitalismo se reproduce en cadena y en diversas escalas. Mientras las comunidades luchen por la solidaridad y cooperación entre sus miembros, a menudo el énfasis a la solidaridad, cohesión y existencia de intereses comunes, haciendo caso omiso esta realidad, que tiende a conducir la acción social a ser promovida a la reproducción del orden social. Al tratar de entender comunidad es fundamental tener en cuenta las relaciones y correlaciones en que están insertadas, pues:

Ellas no son realidades autónomas que pueden traducirse en distintos elementos de la propia sociedad en la que se encuentran. La sociedad, sin embargo, se expresa en diversas situaciones sociales, algunas de las cuales asumen características específicas. 
La comunidad es una de esas situaciones. En este sentido, la comprensión de su realidad presupone la comprensión de la realidad global. A su vez, también sus particularidades propias actúan sobre esta realidad (Souza, 2004, p.64).

Las comunidades tradicionales diferencian sus territorios urbanos, con discontinuidades en la ocupación, y usos temporarios de los espacios como explica Diegues (2002, p.85) afirmando que:

El territorio de las sociedades tradicionales, distinto de los de las sociedades urbanas industriales, es discontinuo, marcada por vacíos aparentes (tierras baldías, estuario que se utilizan para la pesca sólo en ciertas estaciones del año) y ha llevado a las autoridades de conservación a declararlo parte de "áreas protegidas", porque "no es utilizado por nadie". Allí se encuentra a menudo parte del conflicto entre las sociedades tradicionales y las autoridades de conservación.

Por lo tanto, la realidad relativa sobre la producción y el consumo en las comunidades receptoras de turismo también explica el carácter contradictorio de esta actividad, ya que se trata de capitalismo, inherente a su esencia esta la contradicción como hecho notable de este modo de producción, mientras que proporciona entretenimiento para algunos, explora el trabajo de muchos en la misma dinámica. Martins (1999, p.29) dice que "la reproducción ampliada del capital implica la reproducción ampliada de las contradicciones que su movimiento incorpora y genera". En la medida en que los mercados se expanden, se agudizan las contradicciones inmanentes a la producción del espacio que es transformado en recurso especialmente para el turismo, porque el lugar e incluso las personas exóticas son transformados en atractivo turístico. El turismo al instalarse en las comunidades costeras implantando sus emprendimientos desencadena enfrentamientos en duros conflictos entre los residentes y los nuevos promotores de la producción espacial que que desencadenan formas de especulación inmobiliaria con el fin de desplegar sus hoteles o resorts nacionales o de redes internacionales. Cuando la lógica empresarial entra en conflicto con la lógica de las comunidades, cada uno defendiendo sus intereses, casi siempre se lleva la mayor ventaja el más fuerte que tiene mayor capacidad de persuasión.

La expansión capitalista se impone, como Santos dice (1996), con la llamada "integración perversa", que muestra las diferentes formas de participación en el trabajo y en la sociedad. Por lo tanto los pescadores, obreros, campesinos, indígenas sirven como mano de obra temporal y barata, incluidos de manera explorada del trabajo por el turismo, ya que esta actividad paga mal a los proveedores de servicios. Las comunidades de pescadores hacen parte de este proceso y terminan transformándose en centros de receptores de turismo. Cuanto más exótico el lugar, más atractivo para la instalación de los resorts y para la 
promoción del turismo. El turismo es una actividad que implica el uso de los espacios con diversidades de formas de utilización de paisajes y de negocios y de la agilidad a procesos dotados de gran capacidad de organización espacial, instalándose en comunidades. De este modo, se materializa en los lugares, fuera de ellos es pura abstracción.

\section{Principios del turismo comunitario}

El desarrollo de la comunidad requiere un conjunto de principios que dan forma a las estrategias de este desarrollo tales como el principio de las necesidades sentidas: significa que las iniciativas de trabajo en las comunidades tiene que partir de las necesidades sentidas por la población y no sólo de la consecuencia y orientaciones técnicas, de personas externas de la comunidad; principio de la participación: requiere la participación profunda de la población residente en el proceso de construcción de un proceso que bien puede ser considerado como un desarrollo; principio de cooperación, la acción comunitaria no exime a la participación del sector privado o público. Al contrario, se forman alianzas con los sectores público y privado en proyectos de desarrollo comunitario; principio auto-sostenible, los procesos de transformaciones económicas y socio espaciales pueden sufrir discontinuidades, pero precisan ser susceptibles de gestión, mantenimiento y control comunitarios a través de mecanismos que prevengan los efectos adversos de los posibles cambios provocados por intereses externos; principio de universalidad: el éxito esperado es para la población en su conjunto (y no sólo los subgrupos) alterando profundamente las condiciones de subdesarrollo de las comunidades (Carmo 1999, p. 80). La filosofía de trabajo comunitario muestra que no hay ningún misterio cuanto al que se quiere como una comunidad y sociedad:

Sólo la seguridad de lo necesario para una vida digna, la tranquilidad en el relacionamiento social, el sentimiento de participar creativamente en las cosas que suceden, la libertad moderada por las necesidades, la paz del amor, el fomento del

trabajo, la alegría de reír con los demás, el realismo de reírse de sí mismo. Pero, estos objetivos pasan por un valor fundamental que debe ser rescatado: la solidaridad humana (Dowbor, 1998, p. 9).

Las comunidades que luchan por el desarrollo de la comunidad no desconocen la presencia del Estado y la globalización del capital, debido a que viven los conflictos de la inserción en estas realidades cuestionando las políticas neoliberales, en especial la estatal para dirigirlas a los intereses de las economías populares, con resultados más socializados. 


\section{Bibliografia}

Bourdieu, Pierre. O Poder Simbólico. Rio de janeiro: Bertrand Brasil, 2000.

Carmo, Hermano. Desenvolvimento Comunitário. Lisboa: Universidade Aberta, 1999 Castells, Manuel. Fim de milênio. "A era da informação: economia, sociedade e cultura”. São Paulo, Paz e Terra, 1999.

Cazes, Georges. Turismo e subdesenvolvimento: tendências recentes. In: Rodrigues, Adyr B. (Org.). Turismo e geografia: reflexões teóricas e enfoques regionais. São Paulo, Hucitec, 1999.

Diegues, Antonio Carlos. S. Pescadores, camponeses e trabalhadores do mar. São Paulo: Ática, 1983.

. O mito moderno da natureza intocada. $3^{\circ}$ ed. São Paulo: HUCITEC, 2002.

Dowbor, Ladislau. A Reprodução Social. Proposta para uma gestão descentralizada. Petrópolis: Vozes, 1998.

. Da Globalização ao Pode Local: a nova hierarquia dos Espaços. In: FREITAS, Marcos Cézar. A reinvenção do futuro. São Paulo: Cortez,1996.

Maldonado, Simone Carneiro. Mestres e Mares: espaço e indivisão na pesca marítima. 2a. ed. São Paulo: Annablume, 1993.

Martins, Sérgio. Crítica à Economia Política do Espaço. In: DAMIANI, Amélia Luisa; Carlos, Ana Fani Alessandri; Seabra, Odete Carvalho de Lima. O Espaço no fim do Século: a nova raridade. São Paulo: Contexto, 1999.

Sampaio, Carlos Alberto Cioce. Turismo como fenômeno humano: princípios para se pensar a socioeconomia. Santa Cruz do Sul. EDUNISC, 2005.

Santos. Milton. Por uma Geografia Nova. Da crítica da Geografia a uma Geografia Crítica. São Paulo: Edito da Universidade de São Paulo, 1988.

\section{6}

A natureza do espaço: técnica e tempo - razão e emoção. São Paulo: Hucitec,

Souza, Maria Luiza de. Desenvolvimento de Comunidade e Participação. 8a. ed. São Paulo: Cortez, 2004. 
